\title{
Emotions Need to be Defined
}

Thomas Scheff ${ }^{{ }^{*}}$ and Steven Mateo ${ }^{2}$

${ }^{1}$ Department of Sociology, UCSB, University of California, 3009 Lomita Road, Santa Barbara CA, USA

${ }^{2}$ Child Care Worker, Trinity Group Homes Inc, USA

*Corresponding author: Thomas Scheff, Department of Sociology, UCSB, University of California, 3009 Lomita Road, Santa Barbara CA, USA, Tel: (310) 513-2715; E-mail:xscheff@gmail.com

Received date: February 27, 2017; Accepted date: February 27, 2017; Published date: February 28, 2017

Copyright: ( 2017 Scheff T and Mateo S. This is an open-access article distributed under the terms of the Creative Commons Attribution License, which permits unrestricted use, distribution, and reproduction in any medium, provided the original author and source are credited.

\section{Editorial}

All emotion terms, especially in English, are undefined and highly ambiguous. The problem is illustrated by showing the definitions of five emotions, anger, fear, sad, shame and pride, from three of the standard online dictionaries. Each of the five terms is defined in terms of other terms that are themselves undefined: anger, for example, is defined as "upsetness, annoyance, resentment, unfairness, pain, and something bad." None of these terms are defined, and therefore the basic emotions terms are still undefined [1].

An example of one obvious ambiguity is in the definitions of pride. Two different definitions are offered that are exact opposites:

1. A feeling that you respect yourself and deserve to be respected by other people; a feeling that you are more important or better than other people.

The first definition is what might be called authentic pride, the second false pride.

The definitions are given in the order of online sources shown below.

1. www.merriam-webster.com

2. www.dictionary.com

3. www.dictionary.cambridge.org/us/

\section{Angry (adj)}

1. Having a strong feeling of being upset or annoyed.

2. Feeling or showing anger or strong resentment.

3. Having the feeling people get when something unfair, painful, or bad happens.

\section{Afraid (adj)}

1. Filled with fear or apprehension.

2. Feeling fear; filled with apprehension.

3. Feeling fear, or feeling anxiety about the possible results of a particular situation.

Sad (adj)

1. Affected with or expressive of grief or unhappiness.

2. Affected by unhappiness or grief; sorrowful or mournful.

3. Showing, feeling, or causing unhappiness or regret.

\section{Shame (n)}

1. A feeling of guilt, regret, or sadness that you have because you know you have done something wrong; ability to feel guilt, regret, or embarrassment; dishonor or disgrace.

2. The painful feeling arising from the consciousness of something dishonorable, improper, ridiculous, etc., done by oneself or another; disgrace.

3. An uncomfortable feeling of guilt or of being ashamed because of your own or someone else's bad behavior; loss of honor and respect.

\section{Pride (n)}

1. A feeling that you respect yourself and deserve to be respected by other people; a feeling that you are more important or better than other people.

2. A high or inordinate opinion of one's own dignity, importance, merit, or superiority, whether as cherished in the mind or as displayed in bearing, conduct, etc.; a becoming or dignified sense of what is due to oneself or one's position or character; self-respect; self-esteem.

3. A feeling of pleasure and satisfaction that you get because you or people connected with you have done or got something good.

Although there are by now a large number of emotions researchers, most are stilling using the vernacular terms only. Among those who have written about the broad issue of defining emotions, for brevity, only two of the clearest will be mentioned. Jerome Bruner [1] published an extensive discussion of the ambiguities of vernacular emotion words:

Scientists continue to use old, familiar words for emotions... as if the communities that invented these ...terms eons ago possessed a special insight into the basic elements of human nature (p. 323).

Bruner goes on the describe many of the confusions of the ordinary emotion words. This statement is particularly useful in understanding the dilemmas of emotion researchers [1].

Wierzbicka [2] has also called attention to this problem. Her approach is much broader than his, and more systematic. She shows the variations in meaning of emotion terms in different cultures, with the implication that they are therefore somewhat arbitrary.

Compared to understanding of the material world and to behavior, thoughts, attitudes, perception, and beliefs, the realm of emotions is still mostly unknown. But the public and even many researchers don't seem to realize that. For them, their understanding of emotions is based mostly on "common knowledge" which they take for granted without question (Lederman) [3]. Lederman describes how these kinds 
Page 2 of 2

of belief are deeply encrusted by massively repeated iteration over time. Even the psychologist Silvan Tomkins (1963-1994), whose four volumes describe the basic emotions, didn't provide operational definitions [4].

The basis for operational definitions is that they provide measurable dimensions. Of the almost two hundreds studies I have read, only 36 used operational definitions. These studies offer such definitions for anger, fear, grief, pride and shame, but only some of these seem to me to point toward usable definitions.

Given these manifold problems, each observer is free to define emotion terms in their own, un-measurable way. Perhaps we need to define emotions in terms of observables, rather than each other. For example, crying (sobbing with tears) is an observable aspect of some grief. The body heat associated with anger is also an observable. If further observables associated with each emotion were gathered, we could begin scientific studies of emotion.

\section{References}

1. Richard D, Scherer K, Goldsmith H (2003) Behavioral Inhibition, Chapter 17 in Handbook of affective sciences. Oxford University Press, New York,USA.

2. Wierzbica A (1999) Emotions across Language and Cultures. Cambridge University Press, Cambridge, England.

3. Lederman H (2016) On the Early History of Common Knowledge.

4. Silvan T (1963) Affect, Imagery, Consciousness. Springer 1: 4. 